by the fact that there was no significant interaction between rate and list segment in FFR. Rather, Fig. 1 shows that there was a relatively constant difference in FFR for all list segments; the recency items recalled in FFR were evidently encoded in a more stable manner at the slower presentation rate. The IFR and FFR results need not be considered inconsistent. The lack of a recency difference in IFR may have resulted from the Ss' recalling the last-presented items from the STM buffer store. This STM buffer may be able to encode information adequately at a 2 -sec presentation rate and would thus show no rate differences. On the FFR task, the extra processing time afforded the Ss with a 4-sec presentation rate becomes evident and produces a higher level of recall across all serial positions. This hypothesis is compatible with a parallel process model of memory or a sequential model which assumes that transfer from STM and LTM is accomplished by "copying" the information into LTM without affecting its condition in the STM store (e.g., Shiffrin \& Atkinson, 1969).

An alternative to these conceptions of memory has been proposed recently by Craik \& Lockhart (1972). Craik hypothesizes a memory system in which a stimulus is encoded in a number of different levels of memory. Although more processing time is required for storage in the deeper levels, information so processed is likely to produce better retention. In the present experiment, it is possible that IFR results from the final serial positions reflect an economical use of a shallower processing level. Equal recall resulted because the shallow trace had not deteriorated by the time IFR was required. The FFR results may demonstrate retrieval from a deeper level of encoding. Since the presentation rates control to some extent the amount of time available for processing, differences in presentation rate would produce differences in the amount of deeper level encoding. The amount of deeper level encoding could have been responsible for the rate differences which were present across all serial positions in FFR.

\section{REFERENCES}

Baddeley, A., Scott, D., Drynan, R., \& Smith, J. Short-term memory and the limited capacity hypothesis. British Journal of Psychology, 1969, 60, 51-55.

Bartz, W., \& Salehi, M. Interference in short- and long-term memory. Journal of Experimental Psychology, 1970, 84, 380-382.

Cooper, E., \& Pantle, A. The total-time hypothesis in verbal learning. Psychological Bulletin, 1967, 68, 221-234.

Craik, F., \& Lockhart, R. Levels of processing: A framework for memory research. Journal of Verbal Learning \& Verbal Behavior, 1972, 11, 671-684.

Glanzer, M., \& C unitz, A. Two storage mechanisms in free recall. Journal of Verbal Learning \& Verbal Behavior, 1966, 5 , 351-360.

Jacoby, L., \& Bartz, W. Rehearsal and transfer to LTM. Journal of Verbal Learning \& Verbal Behavior, 1972, 11, 561-565.

Shiffrin, R., \& Atkinson, R. Storage and retrieval processes in long-term memory. Psychological Review, 1969, 76, 179-193.

(Received for publication April 23, 1973.)

\title{
Effects of size of ring on backward masking of a disk by a ring*
}

\section{KATHY C. KAO and WILLIAM N. DEMBER \\ University of Cincinnati, Cincinnati, Ohio 45221}

Two experiments are reported on the relation between the size of the masking stimulus (a black ring) and amount of backward masking of the target stimulus (a black disk). Both experiments yielded a significant mask-size effect, but the effect was confined to a very narrow range of masking ring diameters. Under the conditions of these experiments, and within that narrow range, amount of masking is a negatively accelerated increasing function of mask size. This result is consistent with some findings in the masking literature, and is predictable from a particular lateral inhibition model of masking, but it is quite inconsistent with other findings. Some suggested bases for the differences are tentatively offered.

*Supported by Grant GB-33621 to William N. Dember from the National Science Foundation and by Grant EY00481-06 from the National Eye Institute. These experiments were done as part of a master's thesis submitted by $K$. C. Kao to the Graduate Division of the University of Cincinnati. Reprints should be requested from William N. Dember, Department of Psychology, University of Cincinnati, Cincinnati, Ohio 45221.
The two experiments reported here were done as part of a larger project investigating configurational variables in visual backward masking (see, for example, Cox, Dember, \& Sherrick, 1969; Dember \& Stefl, 1972; Sherrick \& Dember, 1970). The variable of concern in the present paper is size of the masking figure. We use the paradigm introduced by Werner (1935), with a black disk at target stimulus and a black ring, fitting snugly around the disk, as mask. Mask size is manipulated by varying the "strip width" of the ring, keeping disk diameter and the inner diameter of the ring constant.

Mask size has been investigated in other studies, with conflicting results. In some (e.g., Matteson, 1969: Werner, 1935), increasing mask size increases amount of masking; in others (e.g., Schiller \& Greenfield, 1969; Sturr, Frumkes, \& Veneruso, 1965), the opposite relation is reported. And in some (e.g., Markoff \& Sturr, 1971; Westheimer, 1967), the function is U-shaped. Unfortunately, these studies differ in many ways, which makes it difficult to identify compelling similarities among those experiments yielding similar functions. 
Table 1

Target Duration Threshold (in Milliseconds) as a Function of Mask Size

\begin{tabular}{cccccccc}
\hline & \multicolumn{7}{c}{ Mask Size (Strip Width in mm) } \\
\cline { 2 - 6 } S & 0 & 2 & 4 & 6 & 8 & 12 & "Infinite" \\
\hline 1 & 5.73 & 29.36 & 26.89 & 28.48 & 23.50 & 29.40 & 34.39 \\
2 & 5.27 & 26.33 & 27.75 & 23.68 & 30.65 & 23.93 & 22.08 \\
3 & 6.28 & 27.30 & 32.47 & 30.77 & 31.95 & 36.16 & 31.37 \\
4 & 8.62 & 29.40 & 30.86 & 27.12 & 30.70 & 31.36 & 27.69 \\
Mean & 6.47 & 28.10 & 29.49 & 27.51 & 29.20 & 30.21 & 28.88 \\
\hline
\end{tabular}

Our interest in mask size stems from its bearing on a theoretical model of masking developed in our laboratory (Purcell \& Dember, 1968; Purcell, Stewart, \& Dember, 1968). Within that model, the masking figure is considered an "insulator" of the target region against lateral inhibitory effects imposed by the illuminated portions of the masking field. The protection thus afforded by the masking figure allows "brightness reversal" of the target region to proceed undiluted; according to the model, it is brightness reversal which, by decreasing the detectability of the target stimulus, is responsible for the masking effect.

From our interpretation of the role of the masking figure, it follows that increasing the strip width of the masking ring will increase amount of masking, at least up to some asymptotic value. Experiment I was designed to test that prediction.

\section{EXPERIMENT I Methods}

\section{Subjects}

Two male and two female college students with normal or corrected-to-normal vision served as paid Ss. The Ss were naive about the purpose of the experiment. Each $S$ received 1 day of practice, consisting of 40 trials on each of seven masking conditions, 20 trials at a target duration of $10 \mathrm{msec}$ and 20 at a duration of $25 \mathrm{msec}$.

\section{Stimuli}

The black target and masks were mounted on gray paper. The target stimulus was a solid disk $8 \mathrm{~mm}$ in diam (subtending $23.5 \mathrm{~min}$ of $\mathrm{arc}$ ). The inner diameter of all the masking rings was also $8 \mathrm{~mm}$. The following values of ring strip width were used: 2 , $4,6,8$, and $12 \mathrm{~mm}$. In addition, one masking stimulus ("infinite") filled the entire viewing field, and one condition was employed with no masking ring. In angular value, the rings had outer diameters of $35.3,47.1,58.9,70.6$, and $94.1 \mathrm{~min}$ of arc; the "infinite" mask subtended $191.1 \mathrm{~min}$ of arc (3 deg $11.1 \mathrm{~min})$.

A light fixation field ( $10 \mathrm{fL}$ ) with four dim red fixation points in a diamond pattern preceded and followed each disk-ring presentation. All stimuli were centered within this pattern.

\section{Procedure}

A completely within-Ss design was used with repeated measures on the one independent variable, mask size. The order of presentation of the seven values of mask size was randomized separately for each $\mathrm{S}$.

The stimuli were presented in the following sequence: fixation field, target, mask, fixation field. The luminance of both the target and the mask field was $10 \mathrm{fL}$. Mask onset coincided with the termination of the target. Mask duration was $100 \mathrm{msec}$, and the interval between trials was kept as close as possible to $10 \mathrm{sec}$.

After 1 practice day, the $S$ received two experimental conditions on each of 3 successive test days and one condition on a 4 th test day. Data collection for one condition took about $40 \mathrm{~min}$; a 10 -min break was given between conditions on those days when two conditions were run. A 5 -min adaptation period preceded each day's testing.

On half the trials, determined randomly, the disk was presented, and on half it was not presented. A trial was init:ated by the S's pushing a button on signal from the $E$. At the end of each trial, the $S$ indicated whether or not the disk had been presented by saying "yes" or "no," guessing if necessary. Viewing was monocular.

The data were collected by the up-and-down double staircase method (Dixon \& Massey, 1969), which used intermixed ascending and descending staircase series in a manner designed to preclude anticipation effects (Cornsweet, 1962). Whether a given trial came from the ascending or descending series was randomly determined, except that each group of 10 trials contained an equal number from each series.

At the beginning of each testing session, for each $S$, a preliminary series of 10 trials was run to obtain a rough estimate of the duration threshold. The end points of the range that were three steps above and four steps below the estimated threshold were used as the starting points of the descending and ascending staircases, respectively.

Target duration constituted the dependent variable. The following rule was employed in varying target duration: If the $S$ responded correctly to a given duration on two successive trials. target duration for the next trial was decreased by $0.5 \mathrm{msec}$; if the $\mathrm{S}$ responded incorrectly (by saying "no" to a disk presentation or "yes" to a blank trial), target duration was increased by $0.5 \mathrm{msec}$ for the next trial. For each $\mathrm{S}$, for each condition, 35 data points were collected for each staircase. The first 5 points on each staircase allowed the two staircases to approach one another. The remaining 30 points per staircase were used in the calculation of a duration threshold according to the computational procedure outlined by Dixon \& Massey (1969).

\section{Results}

The duration threshold for each $\mathrm{S}$ in each condition is given in Table 1. A repeated measures analysis of variance on these data revealed the effect of mask size to be significant $[F(6,8)=31.93, p<.01]$, but the effect is obviously attributable entirely to the difference between the no-mask condition and the six masking conditions. A Newman-Keuls test clearly supports that interpretation.

\section{EXPERIMENT II}

It seems evident that, with our stimuli and general methodology, the mask size effect, if it occurs, is confined to a very small range, specifically between strip width values of 0 and $2 \mathrm{~mm}$. Experiment II was conducted to explore the effect of mask size within that small range. 
Table 2

Target Duration Threshold (in Milliseconds) as a Function of Mask Size

\begin{tabular}{lrrrrrr}
\hline & \multicolumn{6}{c}{ Mask Size (Strip Width in mm) } \\
\cline { 2 - 7 } $\mathrm{S}$ & \multicolumn{1}{c}{0} & \multicolumn{1}{c}{.25} & \multicolumn{1}{c}{.50} & 1.00 & 1.50 & 2.00 \\
\hline 1 & 4.69 & 8.33 & 9.17 & 26.21 & 27.14 & 27.73 \\
2 & 13.02 & 10.52 & 16.35 & 21.56 & 19.52 & 19.93 \\
3 & 4.05 & 8.94 & 13.17 & 16.98 & 27.25 & 27.08 \\
4 & 5.73 & 11.69 & 15.25 & 18.01 & 20.92 & 29.85 \\
Mean & 6.87 & 9.87 & 13.48 & 20.69 & 23.71 & 26.15 \\
\hline
\end{tabular}

Subjects

\section{Method}

Four new paid Ss were run, two males and two females, naive about the purpose of the experiment. They received the same pretraining experience as the Ss in Experiment I.

\section{Stimuli and Procedure}

The stimulus materials, apparatus, design, and procedure were identical to those employed in Experiment II, with one exception. That is, masking ring strip widths were varied over the range from 0 (no mask) to $2 \mathrm{~mm}$. The following specific values were employed: $0, .25, .50,1.0,1.5$, and $2 \mathrm{~mm}$. Skipping the 0 value, these correspond to outer ring diameters of $25.0,26.5$, $29.4,32.4$, and $35.3 \mathrm{~min}$ of arc.

\section{Results}

The duration thresholds for each $\mathrm{S}$ in each condition are given in Table 2. A repeated-measures analysis of variance on these data revealed a significant effect of mask size $[F(5,15)=15.17, \mathrm{p}<.01]$.

For purposes of comparison, note the close correspondence in threshold values for the 0 and $2 \mathrm{~mm}$ conditions in Experiments I and II.

\section{DISCUSSION}

Under the conditions employed in these experiments, increasing mask size does increase amount of masking, as predicted, but only up to an asymptotic strip width value of $2 \mathrm{~mm}$ (a strip width of $6 \mathrm{~min}$ of arc). These results are similar in form to those obtained by Battersby, Oesterreich, \& Sturr (1964), Matteson (1969), and Growney \& Weisstein (1971), despite considerable differences in stimuli, apparatus, methodology, and dependent variable, but opposite to those of Mayzner et al (1965) as well as those of Sturr, Frumkes, \& Veneruso (1965), Sturr \& Frumkes (1968), and Schiller \& Grrenfield (1965). Matteson (1969) has pointed out that both he and Battersby et al (1964) used light stimuli whereas Mayzner et al used black figures on a white background. However, the present results, obtained with black figures, would seem to rule out differences in figure-ground brightness relations as the source of the difference in the form of the size-masking function.

To further complicate matters, there are also reports of U-shaped size-masking functions (e.g., Markoff \& Sturr, 1971; Matthews, 1971; Westheimer. 1965, 1967). These experiments seem to be characterized by the use of very small (1 to 6 min of arc) target stimuli superimposed on relatively large masking disks.

We believe, at this point, that at least two factors are important in determining the shape of the size-masking function: (1) the relative size of target and mask; (2) whether the masking figure overlaps the target or whether the mask contour is concentric to that of the target. Our hunch is that (a) very small targets yield U-shaped functions (see Westheimer, 1965, 1967. for a reasonable account in terms of a Hubel and Weisel type of excitation-inhibition mechanism); (b) overlapping mask-target contours produce decreasing thresholds (less masking) with increasing mask size (reflecting decreasing inhibition of the target by the increasingly distant outer contour of the masking figure); and (c) with relatively large targets and a nonoverlapping target-mask configuration, two sources of masking are operative but act in opposite directions: increasing mask size per se increases amount of masking (in accord with the Purcell et al model), but increasing target-mask border separation decreases amount of masking. It is Case $c$ which generates the negatively accelerated, increasing function found in the present experiments. This analysis seems plausible, but obviously needs to be tested in experiments explicitly designed for the purpose.

\section{REFERENCES}

Battersby, W. S., Oesterreich, R. E., \& Sturr, J. F. Neural limitations of visual excitability. VII. Nonhomonymous retrochiasmal interaction. American Journal of Physiology 1964, 206, 1181-1188.

Cornsweet, T. N. The staircase method in psychophysics. American Journal of Psychology, 1962, 75, 485-491.

Cox, S. I., Dember, W. N., \& Sherrick, M. F. Effect on backward masking of spatial separation between target and mask contours and of target size. Psychonomic Science, 1969, 17, 205-206.

Dember, W. N., \& Stefl, M. Backward enhancement? Science, $1972,175,93-95$.

Dixon, J. W., \& Massey, F. J. Introduction to statistical analysis. New York: McGraw-Hill, 1969.

Growney, R., \& Weisstein, N. Metacontrast and some spatia characteristics of human visual receptive fields. Paper presented at meetings of the Midwestern Psychological Association, 1971.

Markoff, J. I., \& Sturr, J. F. Spatial and luminance determinants of the increment threshold under monoptic and dichoptic viewing. Journal of the Optical Society of America, 1971,61, viewing. Jo $30-1537$.

Matteson, H. H. Effects of surround size and luminance on metacontrast. Journal of the Optical Society of America, $1969,59,1461-1468$

Matthews, M. L. Spatial and temporal factors in masking edges and disks. Perception \& Psychophysics, 1971, 9, 15-22.

Mayzner, M. S., Blatt, M. H., Buschbaum, W. H., Friedel, R. T. Goodwin, P. E., Kanon, D., Kelman, A., \& Wilson, W. D. A $U$-shaped backward masking function in vision: $A$ partial replication of the Weisstein and Haber study with two ring sizes. Psychonomic Science, 1965, 3, 79-80.

Purcell, D. G. \& Dember, $\dot{W}$. $N$. The relation of phenomenal brightness reversal and re-reversal to backward masking and recovery. Perception \& Psychophysics, 1968, 3, 290-292.

Purcell, D. G., Stewart, A. L., \& Dember, W. N. Spatial effectiveness of the mask: Lateral inhibition in visual backward masking. Perception \& Psychophysics, 1968, 4 344-346.

Schiller, P. H. \& Greenfield, A. Visual masking and the recovery phenomenon. Perception \& Psychophysics, 1969, 6, 182-184

Sherrick, M. F., \& Dember, W. N. Completeness and spatia distribution of mask contours as factors in visual backward masking. Journal of Experimental Psychology, 1970, 84, 179-180.

Sturr, J. F., \& Frumkes, T. E. Spatial factors in masking with black or white targets. Perception \& Psychophysics, 1968,4 282-284.

Sturr, J. F., Frumkes, T. E., \& Veneruso, D. M. Spatial determinants of visual masking: Effects of mask size and retinal position. Psychonomic Science, 1965, 3, 327-328.

Werner, H. Studies on coutour: I. Qualitative analyses. American Journal of Psychology, 1935, 47, 40-64.

Westheimer, G. Spatial interaction in the human retina during scotopic vision. Journal of Physiology, 1965, 181, 881-894.

Westheimer, G. Spatial interaction in human cone vision. Journal of Physiology, 1967, 190, 139-154.

\section{NOTES}

1. A preliminary study using signal detection methodology was conducted by Charles Davenport: it failed to yield a significant mask-size effect. Attributing that failure to insensitive methodology, we switched to the procedures described for Experiments I and II. It now appears that Davenport's methodology was not at fault, but rather the values of mask size that were employed.

(Received for publication April 23. 1973.) 